\title{
Bioimpedance Vector Analysis for Heart Failure: Should We Put It on the Agenda?
}

\author{
Bo Liang ${ }^{1 \dagger}$, Rui Li ${ }^{1}$, Jia-Yue Bai ${ }^{2}$ and Ning Gu ${ }^{2 \star t}$ \\ ${ }^{1}$ Nanjing University of Chinese Medicine, Nanjing, China, ${ }^{2}$ Nanjing Hospital of Chinese Medicine Affiliated to Nanjing \\ University of Chinese Medicine, Nanjing, China
}

\section{OPEN ACCESS}

Edited by:

Katrina Poppe,

The University of Auckland,

New Zealand

Reviewed by:

Lilia Castillo-Martinez,

Instituto Nacional de Ciencias

Médicas y Nutrición Salvador Zubirán

(INCMNSZ), Mexico

Pietro Scicchitano,

ASLBari - Azienda Sanitaria Localedella provincia di Bari (ASL

$B A)$, Italy

*Correspondence:

Ning Gu

guning@njucm.edu.cn

TORCID:

Bo Liang

orcid.org/0000-0002-1749-6976

Ning Gu

orcid.org/0000-0003-0704-6768

Specialty section:

This article was submitted to

Heart Failure and Transplantation,

a section of the journal

Frontiers in Cardiovascular Medicine

Received: 20 July 2021 Accepted: 01 September 2021

Published: 28 September 2021

Citation:

Liang B, Li R, Bai J-Y and Gu N (2021)

Bioimpedance Vector Analysis for

Heart Failure: Should We Put It on the

Agenda?

Front. Cardiovasc. Med. 8:744243.

doi: 10.3389/fcrm.2021.744243
Heart failure is a clinical syndrome, resulting in increased intracardiac pressure and/or decreased cardiac output under rest or stress. In acute decompensated heart failure, volume assessment is essential for clinical diagnosis and management. More and more evidence shows the advantages of bioimpedance vector analysis in this issue. Here, we critically present a brief review of bioimpedance vector analysis in the prediction and management of heart failure to give a reference to clinical physicians and guideline makers.

Keywords: bioimpedance vector analysis, heart failure, congestion, risk prediction, management

\section{BACKGROUND}

Heart failure (HF) is a clinical syndrome characterized by signs and symptoms associated with abnormal cardiac function and/or structure, resulting in increased intracardiac pressure and/or decreased cardiac output under rest or stress $(1,2)$. In the developed countries, HF prevalence accounts for about $1 \sim 2 \%$ of the adult population and sharply rises to more than $10 \%$ in people aged 70 or older (3-5). One in six people over the age of 65 who have difficulty breathing due to fatigue or exertion and receive primary care have unidentified $\mathrm{HF}(6,7)$. The lifetime risk of $\mathrm{HF}$ at age 55 years is $33 \%$ for men and $28 \%$ for women (8). Fortunately, based on the temporal trend data of inpatients, the incidence rate of HF may be decreasing $(9,10)$. At present, the definition of HF is limited to the stage of obvious clinical symptoms and signs. Before the clinical symptoms and signs become obvious, patients may show asymptomatic structural or functional cardiac abnormalities, which are precursors of HF (11). The identification of precursors is important since they are associated with poor prognosis (12), and initiation of treatment at the precursor stage can reduce mortality in asymptomatic patients with reduced left ventricular ejection fraction $(12,13)$.

Congestion in $\mathrm{HF}$ is often underdiagnosed. Although international guidelines force physicians to assess the fluid accumulation in patients with $\operatorname{HF}(1,11,14-16)$, most of them are still congested when they are discharged from intensive care units and/or cardiology $(17,18)$. When HF patients are discharged from the hospital with congestion, both mortality and readmission rates increase (19). Early detection of fluid retention is challenging in HF. Recently, bioimpedance vector analysis (BIVA) has emerged as a new tool able to evaluate congestion (20). The electrical impedance field is also corroborated by implanted devices able to assess intrathoracic impedance and communicate data directly via telemonitoring. Here, we present a brief review of BIVA in the prediction and management of $\mathrm{HF}$ to give a reference to clinical physicians and guideline makers. 


\section{BIVA}

BIVA is a portable, non-invasive, simple, and easy auxiliary examination, which dose not expose patients to ionizing radiation and is not affected by differences between observers and investigators (21). BIA works well in healthy subjects and subjects with chronic diseases and is suitable for different races, genders, and ages $(22,23)$. The indicators of the liquid state include extracellular water, intracellular water, and total body water (Figure 1A), which can reflect the distribution of body water composition inside and outside cells. The basic method is to regard the human body as a conducting cylinder. The electrical properties of the fluid inside and outside the human cells and the cell membrane are different so that the impedance generated by the current passing through is different. Then the resistance and capacitive reactance under different currents are measured by the external circuit (Figure 1B). Resistance is mainly determined by the electrical properties of intracellular and extracellular fluids, while capacitive reactance is mainly determined by the capacitive properties between cell membranes $(22,23)$. At present, there are many kinds of electrical circuits to describe the behavior of biologics, the most common and simplest are series connection and parallel connection (Figure 1C). Generally, both resistance and capacitive reactance can be measured at the same frequency [mostly $50 \mathrm{kHz}$ (24), Figure 1D].

Although BIVA has many advantages, there are aspects that need to be paid attention to in our clinical application. Firstly, BIVA measurement of body composition is easily affected by body fluid changes (such as drinking, diet, diarrhea, and exercise) $(32,33)$. Secondly, in order to avoid measurement error, it is necessary to professionally calibrate BIVA equipment regularly for accurate measurement. In addition, although $50 \mathrm{kHz}$ is used as the detection frequency in most cases, different frequencies can result in different measurement (34). It is necessary to study the

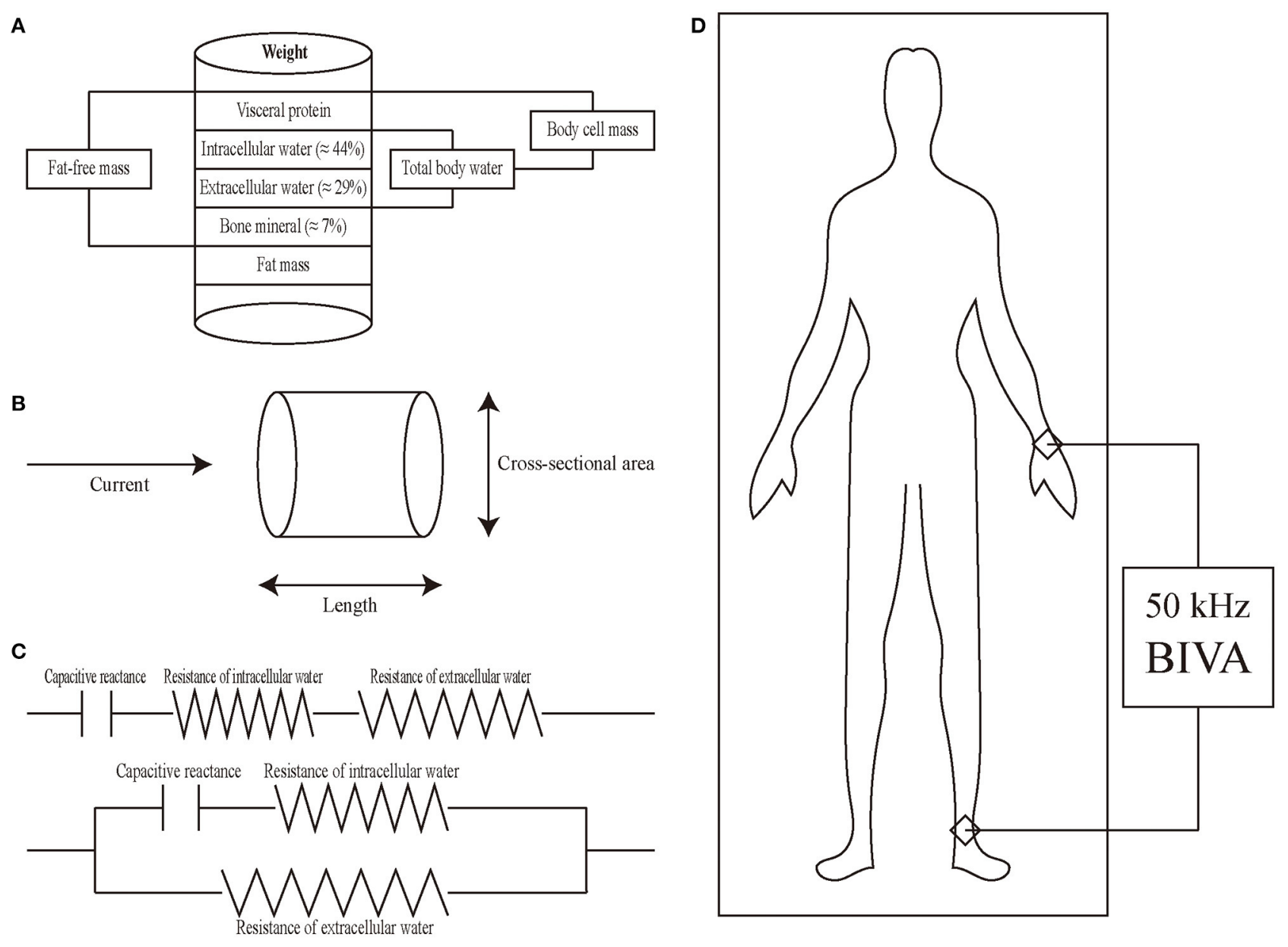

FIGURE 1 | Introduction of BIVA. (A) Schematic diagram of intracellular water, extracellular water, total body water, body cell mass, and fat-free mass. (B) Principles of BIVA from physical characteristics to body composition. Cylinder model for the relationship between impedance and geometry. The resistance of a length of homogeneous conductive material of uniform cross-sectional area is proportional to its length and inversely proportional to its cross-sectional area. (C) The human body consists of resistance and capacitive reactance connected in series (upper) or in parallel (lower). (D) Placement of electrodes in BIVA and total body water is measured by the ankle-wrist bioimpedance method. 
sensitivity and specificity of different frequencies to the human constitution through a large sample study of the population, so as to select the best detection frequency. Finally, BIVA results are also affected by the extremes of body mass index, which is inevitable. It is not recommended to use BIVA for routine evaluation of such patients until accuracy of the BIVA algorithm can be further verified.

\section{CLINICAL APPLICATION OF BIVA}

BIVA identifies the components of bioelectrical impedance and interprets them as a function of fluid status (35) (Figure 1D). Serum colloidal osmolality is the main determinant of peripheral hyperemia in patients with HF by BIVA using a single alternate current frequency of $50 \mathrm{kHz}$ (36), and the advantages of BIVA are it is easy, fast, low cost, and non- invasive $(25,37)$.

A retrospective study of 706 hospitalized patients with acute HF (AHF) showed that the higher the hydration state evaluated by BIVA, the longer the hospital length of stay, suggesting congestion is an independent predictor of the total length of hospital stay in acutely decompensated HF patients (26). BIVA was more accurate than BNP in detecting peripheral congestion in AHF (the area under the curve (AUC) was 0.88 vs. 0.57 respectively; $P<0.001$ ) (25). In addition to AHF, BIVA also has good diagnostic efficacy for chronic HF (CHF). BIVA was more accurate than BNP in detecting peripheral congestion in CHF (AUC was 0.89 vs. 0.68 , respectively; $P<0.001$ ) (25). A prospective trial from Italy indicated that BIVA can effectively predict the total events at admission and discharge (AUC was 0.56 and 0.57 , respectively) (27). In addition to diagnosis, BIVA is also relevant to the management of patients with $\operatorname{HF}(38,39)$. In HF patients, especially those with AHF, a physical examination reflects the degree of rales and lower limb edema, thereby lays the foundation of clinical management. Another study involving
51 emergency patients with suspected AHF from Italy confirmed that the AHF group suffers from greater initial fluid status predicted by BIVA compared with the control group (28). In addition, the hydration state measured by BIVA in the AHF group was significantly decreased $72 \mathrm{~h}$ after diuretic medication treatment and at discharge (28). Routine laboratory testing, such as brain natriuretic peptide (BNP)/N-terminal pro BNP (NT-pro BNP) $(2,40)$, is of great clinical significance for the reaction of peripheral fluid accumulation. BIVA significantly improved the prediction ability of cardiovascular events at 3 months (AUC $=0.97$ ) when combined with clinical symptoms and signs (27). In a small preliminary study of 54 ambulatory patients with HF, BIVA also distinguished between stable and unstable HF. Specifically, patients with stable HF have significantly lower impedance measured fluid load ratio $(\mathrm{Rz} / \mathrm{H})$ and cardiac stress biomarkers, such as NT-pro BNP, than patients with unstable HF (29). The data from 184 patients with AHF and 252 patients with $\mathrm{CHF}$ with a median follow-up of 463 days indicated that the optimum cut-off values for death were estimated plasma volume status $>5.3 \mathrm{dL} / \mathrm{gr}, \mathrm{BNP}>441 \mathrm{pg} / \mathrm{mL}$, hydration index evaluated by BIVA $>73.8 \%$, and blood urea nitrogen/creatinine ratio $(\mathrm{BUN} / \mathrm{Cr})>25(30)$. The mortality of patients with all four indicators above the optimum cut-off values was $93 \%$ higher than that of patients below the optimum cut-off values (30). In addition, an in-hospital resistance variation $(\mathrm{dR} / \mathrm{H})$ increase of more than $11 \Omega / \mathrm{m}$ was related to overall survival (27).

The number of patients with cardiac implantable electronic devices (CIEDs) is increasing all over the world. The use of BIVA in patients having CIEDs is limited because of concerns about electromagnetic interference. However, a study of 200 patients from France indicated that there were no significant changes in battery lead impedance, voltage, or pacing thresholds during BIVA (31). In addition, no changes in CIEDs were found at 0.5 and 1 year of follow-up (31), suggesting that BIVA performance

TABLE 1 | Summary of main findings.

\begin{tabular}{|c|c|c|c|c|c|}
\hline First author & Country & Design & Population & Main findings & References \\
\hline Massari & Italy & $\begin{array}{l}\text { Retrospective } \\
\text { study }\end{array}$ & $\begin{array}{l}487 \mathrm{AHF} \text { and } 413 \\
\mathrm{CHF}\end{array}$ & $\begin{array}{l}\text { BIVA is an easy, fast technique to assess } \\
\text { peripheral congestion, and is even more } \\
\text { accurate than BNP in HF patients. }\end{array}$ & (25) \\
\hline Massari & Italy & $\begin{array}{l}\text { Retrospective } \\
\text { study }\end{array}$ & 706 AHF & $\begin{array}{l}\text { The higher the hydration status, the longer } \\
\text { the hospital length of stay. }\end{array}$ & (26) \\
\hline Santarelli & Italy & $\begin{array}{l}\text { Prospective, } \\
\text { multicenter, } \\
\text { observational } \\
\text { study }\end{array}$ & 336 AHF & $\begin{array}{l}\text { An increase of resistance variation }>11 \Omega / m \\
\text { during hospitalization was associated with } \\
\text { survival. When combined with clinical signs, } \\
\text { BIVA showed a very good predictive value for } \\
\text { cardiovascular events at } 90 \text { days (AUC } 0.97 \text { ). }\end{array}$ & (27) \\
\hline Somma & Italy & Not reported & $51 \mathrm{ADH}$ & $\begin{array}{l}\text { The initial fluid status predicted by BIVA was } \\
\text { greater in the AHF group than the controls. }\end{array}$ & (28) \\
\hline Gastelurrutia & Spain & Not reported & $54 \mathrm{HF}$ & $\begin{array}{l}\text { There were statistical differences between the } \\
\text { stable and non-stable HF patients in the ratio } \\
\text { of impedance-measured fluid overload. }\end{array}$ & (29) \\
\hline Massari & Italy & $\begin{array}{l}\text { Retrospective } \\
\text { study }\end{array}$ & $\begin{array}{l}184 \mathrm{AHF} \text { and } 252 \\
\mathrm{CHF}\end{array}$ & $\begin{array}{l}\text { The optimal cut-off for death occurrence were } \\
\text { hydration index evaluated by BIVA > 73.8\%. }\end{array}$ & (30) \\
\hline Chabin & France & $\begin{array}{l}\text { Prospective } \\
\text { study }\end{array}$ & $200 \mathrm{CHF}$ & $\begin{array}{l}\text { BIVA has no interference in patients equipped } \\
\text { with CIEDs. }\end{array}$ & (31) \\
\hline
\end{tabular}


in patients having CIEDs is secure. A study that included 43 patients from Brazil demonstrated that there were significant reductions in BIVA parameters, including reactance, resistance, and measurements after CIEDs were implanted (41).

In conclusion, current evidence shows that BIVA can be used not only to evaluate the effect of HF treatment but also to predict the total length of hospital stay and the total events of admission and discharge in patients with HF (Table 1). In addition, it is safe and reliable for CIEDs patients (Table $\mathbf{1}$ ).

\section{FUTURE PERSPECTIVES}

Patients with HF are usually admitted to hospital because of symptoms and/or signs of congestion, and fluid overload is the most common cause of readmission (42). In the clinical management of HF patients, adequate fluid volume could improve the short- and long-term outcomes, but most physicians' efforts are concentrated on the identification of peripheral edema, signs of lung congestion, and ascites. Indeed, these are late signs of congestion as they indicate advanced accumulation of fluids. The prognosis of patients at this stage is not ideal. Clinicians should set biomarker and indicator thresholds in order to obtain a sufficient fluid state (38). Rapid and reliable hydration detection provides the possibility of targeted therapy for AHF patients, thus cutting down the length of total hospital stay and treatment costs (26). The simple BIVA mode allows vector displacement as therapeutic feedback to detect, monitor, and even control congestion status (43). BIVA may be used as a routine bedside body fluid assessment and management method (44), however, BIVA is not recommended in the current HF guidelines.

BIVA can classify and rank hydration status without the influence of body weight through comparing with the healthy people norms. These different classifications (normal, under, and over-) and rankings (change relative to pre-treatment) have a wide range of applications in assessing and managing the progress and prognosis of over-hydration (45). The increase of BNP in HF patients from discharge to 1-month follow-up is a helpful prognostic signature for predicting readmission (46). As complementary to BNP, BIVA can provide more accurate prognosis information for patients with HF (30). This could help clinicians to better manage these patients and further reduce the subsequent cardiovascular events (47).

\section{REFERENCES}

1. Ponikowski P, Voors AA, Anker SD, Bueno H, Cleland JG, Coats AJ, et al. 2016 ESC Guidelines for the diagnosis and treatment of acute and chronic heart failure: the Task Force for the diagnosis and treatment of acute and chronic heart failure of the European Society of Cardiology (ESC). Developed with the special contribution of the Heart Failure Association (HFA) of the ESC. Eur J Heart Fail. (2016) 18:891-975. doi: 10.1002/ejhf.592

2. Liang B, Zhao Y-X, Zhang X-X, Liao H-L, Gu N. Reappraisal on pharmacological and mechanical treatments of heart failure. Cardiovasc Diabetol. (2020) 19:55. doi: 10.1186/s12933-020-01024-5

3. Mosterd A, Hoes AW. Clinical epidemiology of heart failure. Heart. (2007) 93:1137-46. doi: 10.1136/hrt.2003.025270
Limitations of BIVA include that it cannot report the bodyweight that would indicate normal fluid status (23). As it requires the application of adhesive electrodes, sweat, hairiness or a patient's inability to cooperate might affect the correct placement of electrodes, thus preventing BIVA measurement. Thirdly, whole-body measurement can provide data indicating excess volume, but its location is not clear. Lung echocardiography can solve this problem jointly $(48,49)$, but it depends on the physicians to determine the location of the abnormal fluid accumulation (39). Finally, combined with clinical signatures, such as BNP/NT-pro BNP (50) and liver stiffness (51), BIVA may improve the ability to the diagnosis and evaluation of HF, especially AHF.

\section{CONCLUSIONS}

For patients with HF, especially AHF, accurate volume assessment is necessary for appropriate management. Although symptoms and signs are the first to be evaluated, the information they provide is still limited. BIVA may make up for this deficiency, though it is not perfect. This challenge can be addressed when physicians integrate clinical and auxiliary assessment.

\section{AUTHOR CONTRIBUTIONS}

BL and NG conceived, designed, or planned the idea. BL drafted the manuscript. NG revised the manuscript. All authors collected and read the literature, read, and approved the final manuscript.

\section{FUNDING}

This work was supported in part by Research and Practice Innovation Plan for Postgraduates of Jiangsu, China [KYCX21_1641], National Natural Science Foundation of China [81774229], Jiangsu Universities Nursing Advantage Discipline Project [2019YSHL095], and Jiangsu Leading Talent Project of Traditional Chinese Medicine [Jiangsu TCM 2018 No. 4].

\section{ACKNOWLEDGMENTS}

We thank all the individuals involved in HF.

4. McLean AS, Eslick GD, Coats AJS. The epidemiology of heart failure in Australia. Int J Cardiol. (2007) 118:370-4. doi: 10.1016/j.ijcard.2006.07.050

5. Savarese G, Lund LH. Global public health burden of heart failure. Card Fail Rev. (2017) 3:7-11. doi: 10.15420/cfr.2016:25:2

6. van Riet EES, Hoes AW, Limburg A, Landman MAJ, van der Hoeven H, Rutten FH. Prevalence of unrecognized heart failure in older persons with shortness of breath on exertion. Eur J Heart Fail. (2014) 16:7727. doi: 10.1002/ejhf.110

7. Filippatos G, Parissis JT. Heart failure diagnosis and prognosis in the elderly: the proof of the pudding is in the eating. Eur J Heart Fail. (2011) 13:46771. doi: 10.1093/eurjhf/hfr036

8. Bleumink GS, Knetsch AM, Sturkenboom MCJM, Straus SMJM, Hofman A, Deckers JW, et al. Quantifying the heart failure epidemic: prevalence, 
incidence rate, lifetime risk and prognosis of heart failure The Rotterdam Study. Eur Heart J. (2004) 25:1614-9. doi: 10.1016/j.ehj.2004.06.038

9. Owan TE, Hodge DO, Herges RM, Jacobsen SJ, Roger VL, Redfield MM. Trends in prevalence and outcome of heart failure with preserved ejection fraction. N Engl J Med. (2006) 355:251-9. doi: 10.1056/NEJMoa052256

10. Gerber Y, Weston SA, Redfield MM, Chamberlain AM, Manemann SM, Jiang R, et al. A contemporary appraisal of the heart failure epidemic in Olmsted County, Minnesota, 2000 to 2010. JAMA Intern Med. (2015) 175:996-1004. doi: 10.1001/jamainternmed.2015.0924

11. Seferovic PM, Ponikowski P, Anker SD, Bauersachs J, Chioncel O, Cleland JGF, et al. Clinical practice update on heart failure 2019: pharmacotherapy, procedures, devices and patient management. An expert consensus meeting report of the Heart Failure Association of the European Society of Cardiology. Eur J Heart Fail. (2019) 21:1169-86. doi: 10.1002/ejhf.1531

12. Wang TJ, Evans JC, Benjamin EJ, Levy D, LeRoy EC, Vasan RS. Natural history of asymptomatic left ventricular systolic dysfunction in the community. Circulation. (2003) 108:977-82. doi: 10.1161/01.CIR.0000085166.44904.79

13. Yusuf S, Pitt B, Davis CE, Hood WB, Cohn JN. Effect of enalapril on mortality and the development of heart failure in asymptomatic patients with reduced left ventricular ejection fractions. N Engl J Med. (1992) 327:68591. doi: 10.1056/NEJM199209033271003

14. Yancy CW, Jessup M, Bozkurt B, Butler J, Casey DE, Drazner MH, et al. 2013 ACCF/AHA guideline for the management of heart failure: executive summary: a report of the American College of Cardiology Foundation/American Heart Association Task Force on practice guidelines. Circulation. (2013) 128:1810-52. doi: 10.1161/CIR.0b013e31829e8807

15. Yancy CW, Jessup M, Bozkurt B, Butler J, Casey DE, Colvin MM, et al. 2016 ACC/AHA/HFSA focused update on new pharmacological therapy for heart failure: an update of the 2013 ACCF/AHA guideline for the management of heart failure: a report of the American College of Cardiology/American Heart Association Task Force on Clinical Practice Guidelines and the Heart Failure Society of America. Circulation. (2016) 134:e282-93. doi: 10.1161/CIR.0000000000000460

16. Yancy CW, Jessup M, Bozkurt B, Butler J, Casey DE, Colvin MM, et al. 2017 ACC/AHA/HFSA focused update of the 2013 ACCF/AHA guideline for the management of heart failure: a report of the American College of Cardiology/American Heart Association Task Force on Clinical Practice Guidelines and the Heart Failure Society of America. Circulation. (2017) 136:e137-61. doi: 10.1161/CIR.0000000000000509

17. Maddox TM, Januzzi JL, Allen LA, Breathett K, Butler J, Davis LL, et al. 2021 Update to the 2017 ACC expert consensus decision pathway for optimization of heart failure treatment: answers to 10 pivotal issues about heart failure with reduced ejection fraction: a report of the American College of Cardiology Solution Set Oversight Committee. J Am Coll Cardiol. (2021) 77:772-810. doi: 10.1016/j.jacc.2020.11.022

18. McDonald M, Virani S, Chan M, Ducharme A, Ezekowitz JA, Giannetti $\mathrm{N}$, et al. CCS/CHFS heart failure guidelines update: defining a new pharmacologic standard of care for heart failure with reduced ejection fraction. Can J Cardiol. (2021) 37:531-46. doi: 10.1016/j.cjca.2021.01.017

19. Ziaeian B, Fonarow GC. The prevention of hospital readmissions in heart failure. Prog Cardiovasc Dis. (2016) 58:37985. doi: 10.1016/j.pcad.2015.09.004

20. Regli IB, Turner R, Woyke S, Rauch S, Brugger H, Gatterer H. Bioelectrical impedance vector analysis: a valuable tool to monitor daily body hydration dynamics at altitude. Int J Environ Res Public Health. (2021) 18:5455. doi: 10.3390/ijerph18105455

21. Almeida YL, Costa Maia CS, Barros NE, Moreno LA, Carioca AAF, Loureiro AC. Is bioelectrical impedance vector analysis a good indicator of nutritional status in children and adolescents? Public Health Nutr. (2021). doi: 10.1017/S1368980021002226. [Epub ahead of print].

22. Kyle UG, Bosaeus I, De Lorenzo AD, Deurenberg P, Elia M, Gómez JM, et al. Bioelectrical impedance analysis-part I: review of principles and methods. Clin Nutr. (2004) 23:1226-43. doi: 10.1016/j.clnu.2004.06.004

23. Kyle UG, Bosaeus I, De Lorenzo AD, Deurenberg P, Elia M, Manuel Gómez J, et al. Bioelectrical impedance analysis-part II: utilization in clinical practice. Clin Nutr. (2004) 23:1430-53. doi: 10.1016/j.clnu.2004.09.012

24. Bernal-Ceballos F, Wacher-Rodarte NH, Orea-Tejeda A, Hernández-Gilsoul T, Castillo-Martínez L. Bioimpedance vector analysis in stable chronic heart failure patients: level of agreement between single and multiple frequency devices. Clin Nutr ESPEN. (2021) 43:206-11. doi: 10.1016/j.clnesp.2021.04.015

25. Massari F, Iacoviello M, Scicchitano P, Mastropasqua F, Guida P, Riccioni G, et al. Accuracy of bioimpedance vector analysis and brain natriuretic peptide in detection of peripheral edema in acute and chronic heart failure. Heart Lung. (2016) 45:319-26. doi: 10.1016/j.hrtlng.2016.03.008

26. Massari F, Scicchitano P, Ciccone MM, Caldarola P, Aspromonte N, Iacoviello $\mathrm{M}$, et al. Bioimpedance vector analysis predicts hospital length of stay in acute heart failure. Nutrition. (2019) 61:56-60. doi: 10.1016/j.nut.2018.10.028

27. Santarelli S, Russo V, Lalle I, De Berardinis B, Vetrone F, Magrini L, et al. Prognostic value of decreased peripheral congestion detected by Bioelectrical Impedance Vector Analysis (BIVA) in patients hospitalized for acute heart failure: BIVA prognostic value in acute heart failure. Eur Heart $J$ Acute Cardiovasc Care. (2017) 6:339-47. doi: 10.1177/2048872616641281

28. Di Somma S, De Berardinis B, Bongiovanni C, Marino R, Ferri E, Alfei B. Use of BNP and bioimpedance to drive therapy in heart failure patients. Congest Heart Fail. (2010) 16(Suppl. 1):S56-61. doi: 10.1111/j.1751-7133.2010.00162.x

29. Gastelurrutia P, Nescolarde L, Rosell-Ferrer J, Domingo M, Ribas N, BayesGenis A. Bioelectrical impedance vector analysis (BIVA) in stable and nonstable heart failure patients: a pilot study. Int J Cardiol. (2011) 146:2624. doi: 10.1016/j.ijcard.2010.10.072

30. Massari F, Scicchitano P, Iacoviello M, Passantino A, Guida P, Sanasi M, et al. Multiparametric approach to congestion for predicting long-term survival in heart failure. J Cardiol. (2020) 75:47-52. doi: 10.1016/j.jjcc.2019.05.017

31. Chabin X, Taghli-Lamallem O, Mulliez A, Bordachar P, Jean F, Futier E, et al. Bioimpedance analysis is safe in patients with implanted cardiac electronic devices. Clin Nutr. (2019) 38:806-11. doi: 10.1016/j.clnu.2018.02.029

32. Campa F, Toselli S, Mazzilli M, Gobbo LA, Coratella G. Assessment of body composition in athletes: a narrative review of available methods with special reference to quantitative and qualitative bioimpedance analysis. Nutrients. (2021) 13:1620. doi: 10.3390/nu13051620

33. Brantlov S, Jødal L, Lange A, Rittig S, Ward LC. Standardisation of bioelectrical impedance analysis for the estimation of body composition in healthy paediatric populations: a systematic review. J Med Eng Technol. (2017) 41:460-79. doi: 10.1080/03091902.2017.1333165

34. Martins PC, Teixeira AS, Guglielmo LGA, Francisco JS, Silva DAS, Nakamura FY, et al. Phase angle is related to $10 \mathrm{~m}$ and $30 \mathrm{~m}$ sprint time and repeatedsprint ability in young male soccer players. Int J Environ Res Public Health. (2021) 18:4405. doi: 10.3390/ijerph18094405

35. Zhu F, Rosales L, Kotanko P. Techniques for assessing fluids status in patients with kidney disease. Curr Opin Nephrol Hypertens. (2016) 25:4739. doi: $10.1097 / \mathrm{MNH} .0000000000000273$

36. Massari F, Scicchitano P, Iacoviello M, Valle R, Sanasi M, Piscopo A, et al. Serum biochemical determinants of peripheral congestion assessed by bioimpedance vector analysis in acute heart failure. Heart Lung. (2019) 48:395-9. doi: 10.1016/j.hrtlng.2019.04.009

37. Barbosa-Silva MCG, Barros AJD. Bioelectrical impedance analysis in clinical practice: a new perspective on its use beyond body composition equations. Curr Opin Clin Nutr Metab Care. (2005) 8:311-7. doi: 10.1097/01.mco.0000165011.69943.39

38. Ronco C, Kaushik M, Valle R, Aspromonte N, Peacock WF. Diagnosis and management of fluid overload in heart failure and cardio-renal syndrome: the "5B" approach. Semin Nephrol. (2012) 32:129-41. doi: 10.1016/j.semnephrol.2011.11.016

39. Tuy T, Peacock WF. Fluid overload assessment and management in heart failure patients. Semin Nephrol. (2012) 32:11220. doi: 10.1016/j.semnephrol.2011.11.014

40. Liang $\mathrm{B}, \mathrm{Gu} \mathrm{N}$. Liraglutide in the treatment of heart failure: insight from FIGHT and LIVE. Cardiovasc Diabetol. (2020) 19:106. doi: 10.1186/s12933-020-01088-3

41. Garlini LM, Alves FD, Kochi A, Zuchinali P, Zimerman L, Pimentel M, et al. Safety and results of bioelectrical impedance analysis in patients with cardiac implantable electronic devices. Braz J Cardiovasc Surg. (2020) 35:16974. doi: 10.21470/1678-9741-2019-0098

42. Savarese G, Bodegard J, Norhammar A, Sartipy P, Thuresson M, Cowie $\mathrm{MR}$, et al. heart failure drug titration, discontinuation, mortality and heart failure hospitalization risk: a multinational observational study (US, UK and Sweden). Eur J Heart Fail. (2021). doi: 10.1002/ejhf.2271 
43. Piccoli A. Bioelectric impedance measurement for fluid status assessment. Contrib Nephrol. (2010) 164:143-52. doi: 10.1159/000313727

44. Stagi S, Irurtia A, Rosales Rafel J, Cabras S, Buffa R, CarrascoMarginet M, et al. Segmental body composition estimated by specific BIVA and dual-energy X-ray absorptiometry. Clin Nutr. (2021) 40:16217. doi: 10.1016/j.clnu.2021.02.043

45. Lukaski HC, Vega Diaz N, Talluri A, Nescolarde L. Classification of hydration in clinical conditions: indirect and direct approaches using bioimpedance. Nutrients. (2019) 11:809. doi: 10.3390/nu11040809

46. Omar HR, Guglin M. Post-discharge rise in BNP and rehospitalization for heart failure. Herz. (2019) 44:450-4. doi: 10.1007/s00059-018-4687-1

47. Di Somma S, Lalle I, Magrini L, Russo V, Navarin S, Castello L, et al. Additive diagnostic and prognostic value of bioelectrical impedance vector analysis (BIVA) to brain natriuretic peptide 'grey-zone' in patients with acute heart failure in the emergency department. Eur Heart J Acute Cardiovasc Care. (2014) 3:167-75. doi: 10.1177/20488726145 21756

48. Öhman J, Harjola V-P, Karjalainen P, Lassus J. Focused echocardiography and lung ultrasound protocol for guiding treatment in acute heart failure. ESC Heart Fail. (2018) 5:120-8. doi: 10.1002/ehf2. 12208

49. Price S, Platz E, Cullen L, Tavazzi G, Christ M, Cowie MR, et al. Expert consensus document: echocardiography and lung ultrasonography for the assessment and management of acute heart failure. Nat Rev Cardiol. (2017) 14:427-40. doi: 10.1038/nrcardio.2017.56
50. Liang B, Qu Y, Zhao Q-F, Gu N. Guanxin V for coronary artery disease: a retrospective study. Biomed Pharmacother. (2020) 128:110280. doi: 10.1016/j.biopha.2020.110280

51. Soloveva A, Kobalava Z, Fudim M, Ambrosy AP, Villevalde S, Bayarsaikhan $\mathrm{M}$, et al. Relationship of liver stiffness with congestion in patients presenting with acute decompensated heart failure. J Card Fail. (2019) 25:17687. doi: 10.1016/j.cardfail.2019.01.020

Conflict of Interest: The authors declare that the research was conducted in the absence of any commercial or financial relationships that could be construed as a potential conflict of interest.

Publisher's Note: All claims expressed in this article are solely those of the authors and do not necessarily represent those of their affiliated organizations, or those of the publisher, the editors and the reviewers. Any product that may be evaluated in this article, or claim that may be made by its manufacturer, is not guaranteed or endorsed by the publisher.

Copyright (c) 2021 Liang, Li, Bai and Gu. This is an open-access article distributed under the terms of the Creative Commons Attribution License (CC BY). The use, distribution or reproduction in other forums is permitted, provided the original author(s) and the copyright owner(s) are credited and that the original publication in this journal is cited, in accordance with accepted academic practice. No use, distribution or reproduction is permitted which does not comply with these terms. 